\author{
Kimitoshi Nakamura $\cdot$ Hiroshi Mitsubuchi \\ Haruhiko Miyayama · Koichi Yatsunami \\ Junji Ishimatsu · Tetsuro Yamamoto · Fumio Endo

\section{Complete absence of bile and pancreatic ducts in a newborn: a new entity of congenital anomaly in hepato-pancreatic development}

Received: 3 March 2003/ Accepted: 9 May 2003 / Published online: 28 June 2003

(C) The Japan Society of Human Genetics and Springer-Verlag 2003

\begin{abstract}
We examined a newborn who had no bile and pancreatic ducts. Hydrops was evident after 29 weeks of gestation and she died shortly after birth, weighing $1,368 \mathrm{~g}$. One of her siblings had died of hydrops at about six months of gestation, and there were two more miscarriages of unknown cause. At autopsy on the newborn, the liver had an abnormally round shape and the pancreas was not in the normal position. There was an ectopic small pancreas with normally developed islets. Histological analysis revealed the complete absence of extra- and intra-hepatic bile and pancreatic ducts. Immunostaining of these tissues showed no positive bile duct marker staining using epithelial membrane antigen and cytokeratin 19 in the liver. Albumin and $\alpha$-fetoprotein staining was positive in the liver, and insulin and glucagon staining was positive in the remaining islets. Thus, this case is characterized by complete absence of bile and pancreatic ducts. These findings suggest the existence of a gene linked to the development of bile and pancreatic ducts.
\end{abstract}

Keywords Bile duct - Congenital anomaly · Development $\cdot$ Hydrops $\cdot$ Pancreatic ducts

K. Nakamura $(\bowtie) \cdot$ H. Mitsubuchi $\cdot$ F. Endo

Department of Pediatrics,

Kumamoto University School of Medicine,

1-1-1 Honjo, Kumamoto 860-8556, Japan

E-mail: kimnak@kaiju.medic.kumamoto-u.ac.jp

Tel.: + 81-96-3735191

Fax: + 81-96-3663471

H. Miyayama $\cdot$ K. Yatsunami $\cdot$ J. Ishimatsu

Kumamoto City Hospital, 1-1-60 Koto,

Kumamoto 862-8505, Japan

T. Yamamoto

Division of Molecular Pathology,

Graduate School of Medical Science,

Kumamoto University School of Medicine,

1-1-1 Honjo, Kumamoto 860-8556, Japan

\section{Introduction}

Liver and pancreatic buds in the human embryo appear from the foregut by four weeks of gestation. Each bud differentiates into tissues such as hepatocytes and bile duct epithelial cells in the liver, exocrine and endocrine cells of the pancreas, and pancreatic duct epithelial cells (Girbert 2000). During the differentiation, each tissue requires a developmental process directed by intracellular signaling, governed by extracellular factors such as cell-to-cell contact, extracellular matrix and various cytokines. These changes are associated with alterations of gene expression, and a stepwise activation of transcriptional factors is required in this process (Duncan 2003; Wilson et al. 2003). Although, precise events have not been elucidated, genes have been reported to be a key factor in the development of liver and pancreas. The abnormal expression of some of these genes is related to pathological features of the liver and pancreas (Duncan 2003; Wilson et al. 2003).

Development of bile duct starts from differentiation of biliary precursor cells from hepatoblasts. The cells form a ductal plate, which is a continuous single-layered ring around the portal mesenchyme. The ductal plate becomes double layered and remodeling of the layer produces a bile duct, which is eventually incorporated into the portal mesenchyme (Lemaigre 2003).

In animal studies, $P d x I$ deficiency and Hlxb9 deficiency lead to agenesis of the pancreas and/or ectopic pancreas (Jonsson et al. 1994; Li et al. 1999; Harrison et al. 1999). $P d x l$ is one of the most important genes during early development of the pancreas and Hlxb9 seems involved in the early development of the dorsal area of the pancreas. In humans, $P D X 1$ deficiency ranges from agenesis of the pancreas to maturity-onset diabetes of the young type 4 (MODY4) (Stoffers et al. 1997a, 1997b). However, pancreatic ducts have not been affected in either PDX1 deficiency or Hlxb9 deficiency. In contrast, patients with Alagille syndrome, which is caused by mutation in the human homologue of 
Jagged-1 (Oda et al. 1997; Li et al. 1997), the paucity or absence of intra-hepatic bile ducts is characteristic; however, congenital absence of interlobular bile ducts has not been noted in this syndrome, and pancreatic ducts are normal in patients with Alagille syndrome. Meckel syndrome is an autosomal recessive disorder characterized by hepatic ductal dysplasia, renal cysts and variably associated features including developmental anomalies of the central nervous system (Blankenberg et al. 1987). However, complete defects of both bile and pancreatic ducts have not been described in the literature.

We investigated a newborn with a defect in extra- and intra-hepatic bile ducts, and the pancreatic duct with an ectopic small portion of the pancreas. The case suggested that there may be a gene responsible for the bile and pancreatic duct development and involved in the development of the pancreas.

\section{Materials and methods}

Specimen

Autopsy tissue was paraffin-embedded and sliced at $4 \mu \mathrm{m}$ for hematoxylin-eosin staining and immunohistochemistry. First antibodies used were rabbit anti-albumin $(1: 100)$, rabbit anti- $\alpha$-fetoprotein (AFP) (1:100), rabbit anti-glucagon (ready-to-use), guinea pig anti-insulin (ready-to-use), mouse anti-cytokeratin 19 (CK19) (1:400) and mouse anti-epithelial membrane (EMA) antigen (ready-to-use) (DAKO, Calif.). DAKO ENVISION kit/horseradish peroxidase (HRP) (DAKO, Calif.) and 3, 3'-diaminobenzidine tetrahydrochloride (DAB) (Sigma, Mo.) were used to detect first antibodies. Paraffin sections of liver and pancreas were processed for light microscopic immunohistochemical analysis, as described (Nakamura et al. 2001).

For immunostaining, sections were incubated with first antibodies at RT for $1 \mathrm{~h}$. Thereafter, they were treated with DAKO ENVISION kit/HRP at RT for $30 \mathrm{~min}$. To detect immunoreactivity, the sections were treated with DAB $(0.8 \mathrm{mM})$ and observed under a fluorescent microscope, model IX70 (Olympus).

Case

An infant was born to a 28-year-old Japanese mother and a 28year-old father after a gestation of 29 weeks and 2 days. The pregnancy, which was the mother's sixth pregnancy, was uneventful until 24 weeks when an ultrasonogram at a local hospital showed the presence of fetal hydrops and oligoamnios. The mother's blood group was B and Rh-positive. A test for parvo B19 IgG was slightly elevated, but IgM was negative. Serological tests for rubella virus, cytomegalovirus and toxoplasma were negative. Two days before admission, contractions began, vaginal bleeding started and the mother was given ritodrine hydrochloride. She came to the hospital in labour pain and with vaginal bleeding. The baby was delivered $1.5 \mathrm{~h}$ after admission. Oligoamnios was present. Apgar scores were 3 (heart rate, muscle tone and reflex irritability) at $1 \mathrm{~min}$ and 1 (heart rate) at $5 \mathrm{~min}$, and the birth weight was $1,368 \mathrm{~g}$. The skin of the infant was edematous and her abdomen was swollen with ascites. Malformation was not obvious from the outside. Cardiopulmonary resuscitation was begun, but her heart rate was $50 / \mathrm{min}$ as a maximum. Low compliance of lungs prevented oxygenation. An umbilical blood specimen was taken for laboratory checks (Table 1). The baby died 58 min after birth.

There was no obvious maternal infection or complication. The mother has a history of six pregnancies with two deliveries (Fig. 1). There was one hydrops baby born at six months of gestation who
Table 1 Laboratory data on cord blood of the newborn

\begin{tabular}{lll}
\hline Variable & This case & $\begin{array}{l}\text { Reference value } \\
\text { (Avery 1999) }\end{array}$ \\
\hline Hematocrit (\%) & 14.3 & $48-69$ \\
White-cell count (per mm3) & $7 \times 10^{3}$ & $9-30 \times 10^{3}$ \\
Platelet count & $332 \times 10^{3}$ & $80-356 \times 10^{3}$ \\
Total protein (g/dl) & 4.3 & $4.8-7.3$ \\
Albumin (g/dl) & 2.6 & $1.8-3.0$ \\
Total bilirubin (mg/dl) & 2.6 & $1.0-2.5$ \\
Aspartate aminotransferase (U/1) & 52 & Up to 54 \\
Alanine aminotransferase (U/l) & 9 & $\mathrm{Up}$ to 50 \\
Lactate dehydrogenase (U/l) & 911 & $160-1,500$ \\
Creatinine kinase (U/l) & 84 & $0-210$ \\
Gamma-glutamyl & 1,017 & $37-193$ \\
transpeptidase (U/l) & & \\
Blood sugar (mg/dl) & 88 & $45-96$ \\
Amylase (U/l) & 3 & $5-65$ \\
Urea nitrogen (mg/dl) & 15.2 & $21-40$ \\
Creatinine (mg/dl) & 0.8 & $0.6-1.2$ \\
Sodium (mmol/l) & 139 & $126-166$ \\
Potassium (mmol/l) & 4.7 & $5.6-12$ \\
Chloride (mmol/l) & 107 & $98-110$ \\
Calcium (mg/dl) & 10.3 & $8.2-11.1$ \\
C-reactive protein (mg/dl) & 0.2 & $0.052-0.133$ \\
\hline
\end{tabular}

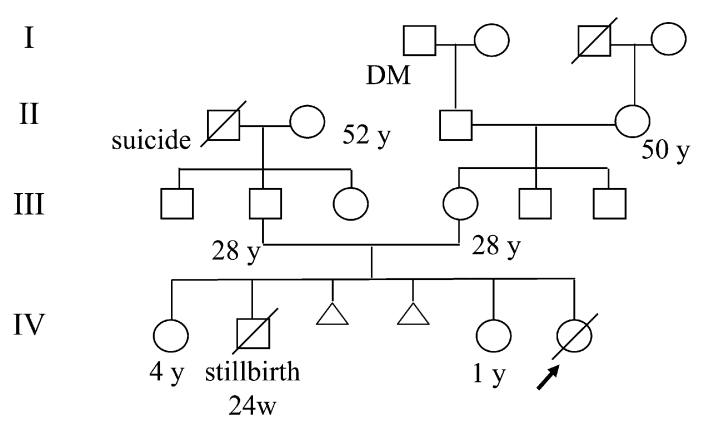

Fig. 1 Pedigree of the newborn showing two healthy but small siblings. Here was one stillborn with hydrops and two spontaneous miscarriages

died soon after delivery. There were two more spontaneous abortions. No consanguinity was noted in the family. Other information related to abnormality in the newborn was not forthcoming from this family.

\section{Results and discussion}

An autopsy on the newborn was done to determine the cause of hydrops and combined abnormalities. The liver had an irregular surface and a nodule-like structure on the cut surface (Fig. 2A). The pancreas was not in the normal position (Fig. 2B, C). Absence of extra-hepatic bile ducts, gallbladder and left kidney, and hypoplasia of the right kidney were evident. The spleen seemed normal with two accessory spleens. An ectopic pancreas $(8 \mathrm{~mm}$ in diameter) was attached to the caudal area of the spleen (data not shown).

Histological investigation of the liver sections stained with hematoxylin and eosin (HE) revealed the presence of fibrosis with reduced numbers of hepatocytes 
Fig. 2A-I Morphology of the liver, digestive system with ectopic pancreas and the kidney in the newborn. A Lateral view of the liver. Nodular surface is obvious. A probe is inserted into the hepatic vein. There is no bile duct. B Digestive system with no pancreas or common bile duct and with pancreas in an abnormal position (arrow). $\mathbf{C}$ Drawing schema of $\mathbf{B}$ for better understanding of the abnormality. (D-I) Microscopic analysis with $\mathrm{H}$-E staining of liver (D-F), pancreas $(\mathbf{G}, \mathbf{H})$, kidney (I) from the newborn
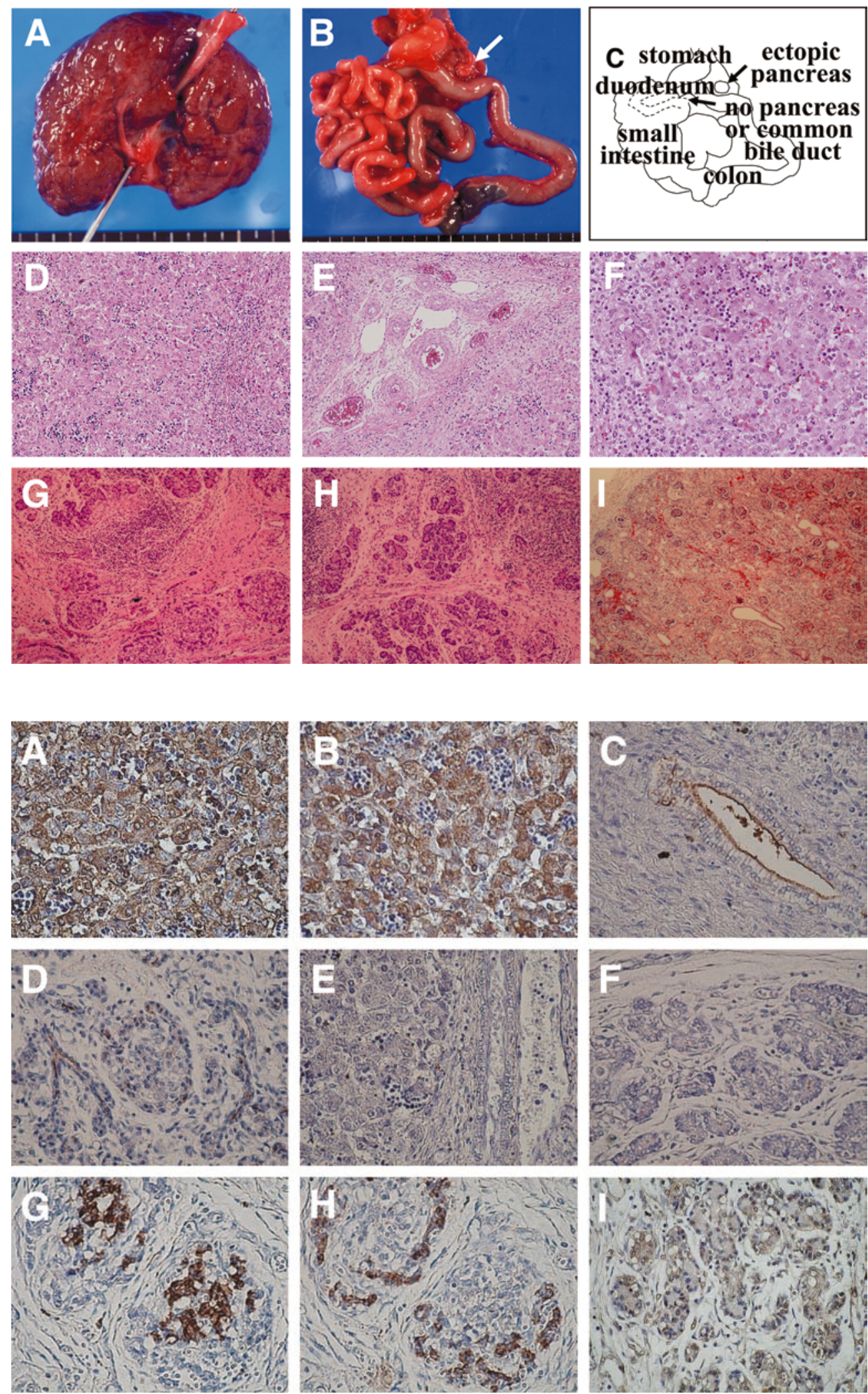

(Fig. 2D). The structure of the liver plate was disrupted and most was occupied by regenerative nodules (Fig. 2D-F). Portal veins and hepatic arteries were present; however, there was no bile duct or a bile duct-like structure in any part of the liver (Fig. 2E, F). Extramedullary hematopoiesis was evident. In the ectopic pancreas, there were islets with an apparently normal structure (Fig. 2G). Mononuclear cells were 
Table 2 Abnormal development of liver, bile duct and pancreas

\begin{tabular}{lll}
\hline Disorder & Pancreas & Bile duct \\
\hline This case & Ectopic & Defect \\
Pancreas defect & Defect of dorsal pancreas & Normal \\
Dorsal pancreas agenesis & Ectopic & Normal \\
Congenital pancreatic agenesis & Ectopic & Normal \\
Hlxb9 deficiency & Ectopic - MODY4 & Normal \\
$P d x 1$ deficiency & $\beta$ cell defect & Normal \\
Pancreatic $\beta$ cell agenesis & $\alpha$ cell defect & Normal \\
Pax6 deficiency & & \\
Bile duct defect & Normal & Intrahepatic hypoplasia \\
Alagille syndrome & Normal & Intrahepatic hypoplasia \\
Meckel syndrome & & \\
\hline
\end{tabular}

infiltrated particularly in the exocrine area of the pancreas (Fig. 2H). Numbers of acinar cells were markedly reduced and were replaced by the mononuclear cells. There was no pancreatic duct or duct-like structure in the any area of the pancreas. In the kidney, glomeruli and renal tubules were normally present with no infiltration of inflammatory cells (Fig. 2I).

Immunological analysis of the liver showed the hepatocytes to be positive for anti-albumin and $\alpha$-fetoprotein staining (Fig. 3A, B). As a control, we used a 30-week gestated newborn specimen from autopsy. In the control liver and pancreas, epithelial cells of ducts were positively stained with anti-EMA antibodies (Fig. 3C, D). In contrast, there were only a few cells positive for staining with anti-EMA antibodies in the liver and pancreas from the newborn (Fig. 3E, F). In addition, positive cells were present only in the primitive duct-like structure. These findings are consistent with observations on the liver and pancreas in case of the HE staining in which a structure of bile and pancreatic ducts was not evident.

Immunostained islets in the ectopic pancreas were positive for glucagon and insulin (Fig. 3G, H); however, there were notable variations in sizes of these islets. In the large islets, there was an ordered distribution of glucagon-positive cells and insulin-positive cells; the glucagon-positive cells were outside and insulin-positive cells were inside, the same as mature islets. The small islets were in clusters formed by insulin- and glucagon-positive cells, and these small islets were scattered between mature islets. However, the organization seen in larger islets was not recognized in these small islets. Amylase-positive cells were present in the exocrine region of pancreas (Fig. 3I); however, these cells are not associated with epithelial cells of the pancreatic duct.

These investigations revealed that visceral areas of pancreatic as well as both intra-and extra-bile ducts were absent, with the presence of liver fibrosis. The case is distinct from a bile duct atresia, because the case has a deficiency of both intra- and extra-hepatic bile duct and presence of lesion in the pancreas. Immunostaining of ductal epithelial cells demonstrated that only small numbers of duct epithelial cells were present in the liver and pancreas with no organization of a duct structure.
These observations suggested that the defects might exist at the developmental process of ducts that are common to both liver and pancreas.

There are only a few reports describing congenital defects in the development of the pancreas, including agenesis of beta cells, functional defects in endocrine cells, dysfunction of both endocrine and exocrine cells (Wildling et al. 1993; Stoffers et al. 1997b). Developmental defects in the pancreas were often related to dysfunction of genes contributing to early development of the pancreas (Wilson et al. 2003). Pdx1 is a transcription factor expressed in the foregut and is essential for development of pancreatic buds. In humans, defects in the PDX1 gene lead to agenesis of the pancreas (Stoffers et al. 1997b). Animal models on developmental abnormalities of the pancreas, including Pdxl-, Hlxb9- and Hesl-knockout mice have been described. $P d x 1$-null mice are embryonic lethal at 6.5 days after birth and showed agenesis of the pancreas (Jonsson et al. 1994). Hlxb9-null mice had agenesis of the dorsal pancreas and died immediately after birth due to insufficiency of insulin secretion ( $\mathrm{Li}$ et al. 1999; Harrison et al. 1999). Hes I-null mice developed hypoplasia of the pancreas with increased numbers of alpha cells (Jensen et al. 2000). However, there were no specific genes described as being related to development of agenesis of the pancreatic duct. Thus, animal studies on the development of liver and pancreas did not show any specific genes involved in the development of both pancreatic and hepatic ducts (Table 2).

In the mother, there were two sporadic miscarriages and one sibling had hydrops. This history suggested that there is a genetic factor related to defects in the liver and pancreas. These findings strongly suggest that this maybe a new entity of genetic defect related to the development of pancreatic and hepatic ducts.

Acknowledgements We thank Ms. T. Kubo for her superb histological assistance. We also thank Ms. M. Ohara for her proofreading of the manuscript. This work was supported in part by grants for Research for the Future Program of JSPS, Grant-in-Aid for Scientific Research and Grant-in-Aid for 21st Century COE Research from the Ministry of Education, Science, Technology, Sports and Culture. "Cell Fate Regulation Research and Education Unit" and a Research Grant from the Ministry of Health, Labour and Welfare. 


\section{References}

Avery GB (1999) Neonatology, 5th edn. Lippincott, Williams \& Wilkins, Philadelphia

Blankenberg TA, Ruebner BH, Ellis WG, Bernstein J, Dimmick JE (1987) Pathology of renal and hepatic anomalies in Meckel syndrome. Am J Med Genet Suppl 3:395-410

Duncan SA (2003) Mechanisms controlling early development of the liver. Mech Dev 120:19-33

Girbert SF (2000) Developmental Biology, 6th edn. Sinauer, Sunderland, Massachusetts

Harrison KA, Thaler J, Pfaff SL, Gu H, Kehrl JH (1999) Pancreas dorsal lobe agenesis and abnormal islets of Langerhans in Hlxb9-deficient mice. Nat Genet 23:71-75

Jensen J, Pedersen EE, Galante P, Hald J, Heller RS, Ishibashi M, Kageyama R, Guillemot F, Serup P, Madsen OD (2000) Control of endodermal endocrine development by Hes-1. Nat Genet 24:36-44

Jonsson J, Carlsson L, Edlund T, Edlund H (1994) Insulinpromoter-factor 1 is required for pancreas development in mice. Nature 371:606-609

Lemaigre FP (2003) Development of the biliary tract. Mech Dev 120:81-87

Li H, Arber S, Jessell TM, Edlund H (1999) Selective agenesis of the dorsal pancreas in mice lacking homeobox gene Hlxb9. Nat Genet 23:67-70
Li L, Krantz ID, Deng Y, Genin A, Banta AB, Collins CC, Qi M, Trask BJ, Kuo WL, Cochran J, Costa T, Pierpont MEM, Rand EB, Piccoli DA, Hood L, Spinner NB (1997) Alagille syndrome is caused by mutations in human Jagged1, which encodes a ligand for Notch1. Nat Genet 16:243-251

Nakamura K, Robertson M, Liu G, Dickie P, Nakamura KT, Guo JQ, Duff HJ, Opas M, Kavanagh K, Michalak M (2001) Complete heart block and sudden death in mice overexpressing calreticulin. J Clin Invest 107:1245-1253

Oda T, Elkahloun AG, Pike BL, Okajima K, Krantz ID, Genin A, Piccoli DA, Meltzer PS, Spinner NB, Collins FS, Chandrasekharappa SC (1997) Mutations in the human Jagged1 gene are responsible for Alagille syndrome. Nat Genet 16:235-242

Stoffers DA, Ferrer J, Clarke WL, Habener JF (1997a) Early-onset type-II diabetes mellitus (MODY4) linked to IPF1. Nat Genet 17:138-139

Stoffers DA, Zinkin NT, Stanojevic V, Clarke WL, Habener JF (1997b) Pancreatic agenesis attributable to a single nucleotide deletion in the human IPFI gene coding sequence. Nat Genet 15:106-110

Wildling R, Schnedl WJ, Reisinger EC, Schreiber F, Lipp RW, Lederer A, Krejs GJ (1993) Agenesis of the dorsal pancreas in a woman with diabetes mellitus and in both of her sons. Gastroenterology 104:1182-1186

Wilson ME, Scheel D, German MS (2003) Gene expression cascades in pancreatic development. Mech Dev 120:65-80 